\title{
Reflexões sobre as Práticas Docentes e o Sujeito Discente no Ensino Superior: Contribuições da Andragogia
}

\author{
Alcylanna Nunes Teixeira ${ }^{1}$; Antoniel dos Santos Gomes Filho ${ }^{2}$; Tamyris Madeira de Brito ${ }^{3}$; \\ Zuleide Fernandes de Queiroz ${ }^{4}$
}

\begin{abstract}
Resumo: O estudo versa sobre as discussões acerca das práticas docentes no ensino superior, questões didáticas e metodológicas no processo construção do conhecimento no cenário atual da educação e da ensinagem no ensino superior, ressaltando as contribuições da perspectiva andragógica para alicerce didático no exercício da docência. Objetivamos aqui realizar uma reflexão crítico-analítica sobre andragogia no ensino superior, as práticas docentes e o reconhecimento do sujeito aprendente. Para tal, faz-se uso da revisão bibliográfica, com delineamento qualitativo e característica descritiva-analítica, discutindo questões acerca do cenário contemporâneo no Ensino Superior, as práticas docentes que perpassam a pedagogia histórico-crítica, a didática, a andragogia e o reconhecimento das experiências de vida do sujeito discente nos processos de aprendizagem e construção do conhecimento.
\end{abstract}

Palavras-Chave: Ensino Superior. Práticas Docentes. Sujeito Discente. Andragogia.

\section{Reflections on Teaching Practices and the Student Subject in Higher Education: Contributions from Andragogy}

\begin{abstract}
The study focuses on the discussions about teaching practices in higher education, educational and methodological issues in the process of knowledge construction in the current scenario of education and ensinagem in higher education, emphasizing the contributions of andragógica perspective for educational foundation in the exercise of teaching. Here we aim to achieve a critical-analytical reflection on andragogia in higher education, the teaching practices and the recognition of the subject learner. To do this, it is the use of literature review, with a qualitative and descriptive-analytical characteristic, discussing questions about the contemporary scene in Higher Education, the teaching practices that pervades the historical-critical pedagogy, didactics, andragogia and the recognition of the life experiences of the subject students in the learning processes and knowledge construction.
\end{abstract}

Keyworks: Higher Education. Teaching Practices. Subject Students. Andragogia.

\footnotetext{
${ }^{1}$ Mestranda no Programa de Pós-graduação em Desenvolvimento Regional Sustentável (PRODER) pela UFCA. Bolsista CAPES. Professora da Faculdade Vale do Salgado - FVS. Pós-graduada em Ciências da Educação e Docência do Ensino Superior pela FVS. E-mail: alcylannanunes@gmail.com

2 Mestre em Educação pela Universidade Federal do Ceará. Professor da Faculdade Vale do Salgado. E-mail: antonielsantos@fvs.edu.br

${ }^{3}$ Mestranda no Programa de Pós-graduação em Desenvolvimento Regional Sustentável (PRODER) pela UFCA. Docente

UNILEÃO. E-mail: professoratamyrismadeira@ hotmail.com

${ }^{4}$ Doutora em Educação pela UFC. Professora Programa de Pós-graduação em Desenvolvimento Regional Sustentável (PRODER) pela UFCA. E-mail: zuleidefqueiroz@gmail.com;
} 


\section{Introdução}

As questões ligadas ao ensino superior expressam diversas facetas que se tornam desafios significativos para a Instituição de Ensino Superior (IES), imprimindo reflexos à gestão, aos docentes e discentes envolvidos. As demandas da conjuntura sociopolítica no âmbito educacional incidem no processo de formação crítica e profissional, onde a racionalização torna-se a nova força do homem, pela qual o homem pode intervir no mundo natural e social (GOERGEN, 2005).

Os meios sociais, econômicos e políticos estão apontando cada dia mais para novas formas de interagir na sociedade, o que reflete de forma significativa no âmbito educacional, em especial no nível superior. Os processos de construção de conhecimento e a formação pessoal e profissional através deste nível de escolaridade tornam a figura do docente um mediador diante das demandas emergentes do mundo da informação e tecnologia, proporcionando ao sujeito discente que o mesmo (re)construa a sua realidade individual e coletiva.

No Brasil, são ofertados 33 mil cursos de graduação em 2.364 instituições de ensino superior. Os dados relativos ao ano de 2015, divulgados pelo Instituto Nacional de Estudos e Pesquisas Educacionais Anísio Teixeira (INEP) revelam a trajetória dos alunos entre 2010 e 2014. Em 2010, 11,4\% dos alunos abandonaram o curso para o qual foram admitidos. Em 2014, esse número chegou a 49\%. Até o final de 2016, 8.033.574 alunos estavam matriculados no ensino superior, o que supera a estatística de 2014 em 2,5\%, quando havia 7.839.765 matriculados (BRASIL, 2016).

Dentre as problemáticas encontradas no ensino superior, a evasão chama atenção, e Lobo (2012), sinaliza as causas mais relevantes: a inadaptação do ingressante ao estilo do ensino superior e falta de maturidade; formação básica deficiente; dificuldade financeira; irritação com a precariedade dos serviços oferecidos pela IES; decepção com a pouca motivação e atenção dos professores; dificuldades com transporte, alimentação e ambientação na IES; mudança de curso e mudança de residência.

Desse modo, faz-se necessário compreender a realidade supracitada em sua complexidade, mas de forma especial, revisitar em caráter continuado as práticas docentes percebendo a importância de reavaliação na abordagem da educação e do processo de ensinoaprendizagem, de modo que a proposta didática aproxime o aprendente da realidade, apresentando articulação teórica-prática na perspectiva de aplicabilidade cotidiana do 
conhecimento a ser construído, uma vez que, no âmbito do ensino superior o público alvo é composto predominantemente por jovens e adultos.

O discente contemporâneo é reflexo das demandas e mudanças emergentes, momento complexo e imediato, de novas expectativas e múltiplos interesses. São transformações necessárias, o que nos conduz ampliar o olhar no que diz respeito à aplicabilidade das teorias, de modo a integrá-las de acordo com as especificidades vigentes na atualidade (ARROYO, 2014).

É possível incitar o olhar para a andragogia, que é pautada nos princípios da Horizontalidade e Participação ativa. Cavalcanti (2017) ressalta que Malcolm Knowles ao final do século IX já suscitava o modelo andragógico, entendendo meios para a aprendizagem de adultos que versa por facilitar caminho consciente e significativo para o conhecimento, baseado nas seguintes premissas: necessidade de conhecer; autoconceito do aprendiz; o papel da experiência; prontidão para aprender; orientação para aprendizagem e motivação.

Tais premissas coadunam com a Aprendizagem Significativa de David Ausubel, para ele em 1963, o fator que mais influência a aprendizagem é aquilo que o aluno já sabe e que pode funcionar como ancoragem para as novas idéias. Sua estrutura cognitiva, sua experiência de vida, habilidades, expectativas pessoal e profissional, fatores que despertam interesse e estimula o discente, este como material potencialmente significativo no processo de aprendizagem (MORAN, 2013).

Nesse momento, faz-se necessário tecer reflexões sobre o reconhecimento da experiência de vida dos discentes como uma ferramenta de produção do conhecimento. A subjetividade se torna saliente no cenário de ensino, principalmente no que diz respeito ao Ensino Superior (ES), entendendo que os discentes são jovens e adultos aprendentes que trazem consigo uma expressão pessoal da visão de homem e de mundo, que encontram suas raízes nas experiências de vida, construtos subjetivos e sociais do espaço em que vive (STELLA, 2007).

Dessa forma, temos como objetivo realizar a reflexão critico-analítica sobre a construção de conhecimento no ensino superior e o uso da andragogia nas práticas docentes. Debatendo aspectos sobre a importância do reconhecimento das experiências de vida dos discentes para como sujeito do processo de aprendizagem, partícipe ativo do mesmo.

No tocante ao método, apresentamos um estudo de abordagem qualitativa através de uma revisão de literatura na perspectiva crítico-analítico, com base em dados coletados através da leitura seletiva de 12 livros, 28 artigos, resultando no uso de 9 livros e 10 artigos que melhor discutiam a temática delimitada, considerando como critério de inclusão os autores mais contemporâneos que adotam reflexão crítica diante das demandas atuais, já os critérios de 
exclusão foram compostos por estudos cujo os conteúdos seguiam bases tradicionais e com especificidades que não contemplavam o âmbito educacional sobre Ensino Superior. Usamos para tal, os seguintes descritores: educação; ensino superior; docência; docente; discente e andragogia.

O presente estudo manifesta a relevância social no que tange o papel do Ensino Superior na construção de conhecimento e formação de profissionais. No âmbito acadêmico incitará reflexões que proporcionarão avaliação em direção à formação inicial e continuada do docente do Ensino Superior, bem como contribuirá com a ampliação do conhecimento pessoal sobre a temática em estudo.

\section{Educação no Ensino Superior e Práticas Docentes}

Aspectos fundamentais do âmbito educacional são entendidos através dos caminhos políticos até então percorridos. A política educacional passou por várias revisões, e dentre elas, as questões levantadas a partir do Relatório de Delors ${ }^{5}$, produzido entre 1993 e 1996 pela Comissão internacional sobre Educação para o Século XXI promovida pela Organização das Nações Unidas para a Educação, a Ciência e a Cultura (UNESCO), repercutiu de modo que se torna emergente cuidar das tensões ligadas à

[...] tornar-se cidadão do mundo, mantendo a ligação com a comunidade; mundializar a cultura, preservando as culturas locais e as potencialidades individuais; adaptar o indivíduo às demandas de conhecimento científico e tecnológico - especialmente as tecnologias de informação -, mantendo o respeito por sua autonomia; conciliar a competição à cooperação e à solidariedade; respeitar tradições e conviç̧ões pessoais e garantir a abertura ao universal (SHIROMA; MORAES; EVANGELISTA, 2007, p. $55)$.

A conjuntura atual brasileira no tocante as instituições de ensino superior, exprime conformidade com a Lei de Diretrizes e Bases - LDB No 9.394/96, permitindo para o professor a docência, como atividade comum à Universidade, Centros Universitários, Faculdades Integradas, Institutos ou Escolas Superiores. Desse modo, a docência no ensino superior não é formada, mas sim preparada nos programas de pós-graduação, refletindo sobre elementos necessários tanto para a pesquisa como para os processos de ensino, superando a simples transmissão de conteúdos (PIMENTA; ANASTASIOU, 2014).

\footnotetext{
${ }^{5}$ O Francês Jacques Delors coordenou a Comissão internacional sobre Educação para o Século XXI, formulada pela Unesco, delineando a revisão da política educacional de vários países.
} 
O cenário da educação no Brasil vem representando a dinâmica política e social pautada no pragmatismo ideal da economia e dos processos de globalização, voltando-se para os fins e, o que há de mensurável e no âmbito do ensino e da prática educacional. O Ensino superior é percebido um motor do desenvolvimento econômico, no entanto, o desafio aqui se constitui em fazer jus à "educação ao longo de toda a vida" pautada em quatro processos de aprendizagem: aprender a conhecer, aprender a fazer, aprender a ser e aprender a viver junto (SHIROMA; MORAES; EVANGELISTA, 2007; PIMENTA, 1997).

Ao professor é sempre delegado o papel da mudança, com vistas à realização do ideário, levando consigo a missão edificante da educação para a vida humana e para o bom funcionamento da sociedade. Por vezes essa educação é entendida como co-responsabilidade da Família como núcleo básico de educação desde infância, a gestão com o funcionamento em adequação ao sistema vigente e, os professores como agentes mediadores da formação profissional e preparação cidadã para a vida em sociedade, contemplando no ensino superior o momento de ressignificação da aprendizagem para a construção do conhecimento profissional.

Dar-se aqui então, lugar a reflexividade ancorada por Libâneo quando o fazer docente deve constituir-se também da condição estrutural cognitivo-reflexiva pela qual o professor representa seus ideais e práticas possíveis, articulado a cada contexto, a cada cenário em seu tempo. A perspectiva da reflexibilidade contribui com a compreensão do pensamento pósmoderno, considerando os frutos dos avanços tecnológicos e científicos que alteraram nos processos de produção, empoderamento dos sujeitos e flexibilidade profissional (LIBÂNEO, 2006).

Assim, é possível distinguir características do professor reflexivo e o dito críticoreflexivo, onde o primeiro é representado pela abordagem pragmática, em uma busca de fazer e pensar a relação teórica-prática, atuando na realidade instrumental, pronta e certamente acabada (aplicação da teoria à prática), já o professor crítico-reflexivo repensa sua ação frente ao mundo capitalista, como agente em uma realidade social construída e inacabada, atua de modo que a compreensão subjetiva do real orienta a comunicação e a reconstrução de suas práticas (articulação das interpretações teóricas e experiências práticas a partir da realidade emergente) (LIBÂNEO, 2006).

A prática na maioria das vezes chega enriquecida de ideais e expectativas subjetivas, culturais, políticas, econômicas e sociais, sem dar-se conta da reflexibilidade humana na contemporaneidade que deságuam nas demandas emergentes da sociedade, esta como realidade subjetiva que é composta por vários aspectos da relação do sujeito com o seu ambiente, com seu mundo apreendido e reconhecido como tal (BERGER; LUCKMANN, 2012). 
Educar, ensinar, aprender. Ensinar a aprender, aprender a educar, aprender a aprender ensinar. É assim que nos colocamos a refletir sobre o papel docente, nos permitindo estender o olhar para as teorias sobre a educação ${ }^{6}$ coadunando com Saviani (2011) ao constituir o que ele chamou de primeiras aproximações da Pedagogia histórico-crítica, levantando dimensões políticas e sociais ancoradas aos escopos educacionais, consentindo a perspectiva de continuidade e ampliação do fenômeno educacional através da construção de práxis educativas que abordem a singularidade humana considerando as dimensões que mesma vem sendo constituída.

Estamos envolvidos em um movimento de transição que reflete processos de mudanças, mas não as concretizam. É necessário reconhecermos o que fomos, os nossos valores, o que nos permite ser o que somos no presente, nossa dinâmica social e a constante busca de afirmação pessoal nos estrutura a pensar o amanhã e saber o que seremos, assumindo então, a coresponsabilidade uma relação retroalimentar através do papel profissional, que nos coloca a refletir e agir de modo a contribuir comprometido com si e a com a sociedade (FREIRE, 2007).

Pensar educação nesse cenário é entender o homem enquanto sujeito existente, ativo socialmente ontem, hoje e amanhã, direto ou indiretamente influenciado por dimensões culturais, sociopolítica e econômica do processo de globalização e os consequentes avanços tecnológicos que constitui a sociedade da informação, gerando demandas educacionais cada vez mais complexas, com resoluções emergentes solícitas aos manejos do professor.

O sujeito contemporâneo transita na maioria das vezes em movimentos de resistências e busca de singularidade, humanização e leveza nos processos imediatistas e mensuráveis do sistema pós moderno. Arroyo (2014) passa a refletir à luz de Paulo Freire sobre os sujeitos de mudança, em processo de empoderamento e subjetivação frente à sociedade tradicionalmente pautada na 'educação bancária', desde então representando resistências e ganhando forças com os movimentos sociais.

Em Arroyo (2014) face aos processos emergentes, foi demandando do docente uma compreensão de como se configura o cenário produtor de outros sujeitos, com suas necessidades particulares e expressão de resistência como o fenômeno subjetivo implicado no âmbito educacional, conduzindo a repensar as relações de ensino - aprendizagem, o papel do professor e outros métodos pedagógicos, principalmente para adultos. Momento de ressignificar o papel docente.

\footnotetext{
${ }^{6}$ Saviani (2011, p.115) retoma o termo sugerido por Luiz Antônio Cunha para esclarecer o uso da expressão crítico-reprodutivismo para caracterizar os limites de várias teorias da educação, e usa o momento para aprofundar a crítica ampliando questões sobre a educação.
} 
A experiência, o conhecimento, os saberes pedagógicos e sobre a educação se constituem a partir da prática vivenciada, refletida e reelaborada em outras práticas que dão formas e significados a profissão docente. Pimenta (1997) em seus estudos sobre formação de Professores, levantava questões sobre a construção da identidade do Professor, ressaltando a importância do reconhecimento do professor como sujeito historicamente situado frente às demandas sociais.

\footnotetext{
Uma identidade profissional se constrói, pois, a partir da significação social da profissão; da revisão constante dos significados sociais da profissão; da revisão das tradições. Como, também, de práticas consagradas culturalmente e que permanecem significativas (PIMENTA, 1997, p. 7).
}

Do mesmo modo, Giroux (1997) passa a tecer estudos sobre o professor, este como intelectual, rico em saberes e fundamentações ampliadas para construções da ciência e profissão docente. Seguindo, é possível agregar Contreras (2002) que expressa seus estudos sobre a autonomia do professor e que assume o papel de pesquisador, com perspectiva exploratória e em contínua formação; já em Libâneo (2006) passamos a compreender os construtos sobre reflexividade, bem como a ampliação do olhar para o professor reflexivo, em um entendimento crítico e expansivo trazido por Pimenta, Ghedin, et al (2006).

Situamos então a docência com face aos estudos até então citados, abordando a diante reflexões que contemplam um alicerce de base Freiriana, pautada na transição, nas mudanças, na autonomia e empoderamento que concerne aos sujeitos da educação, ancorando com a consistência da perspectiva histórico-crítica a luz de Saviani (2011), considerando as demandas emergentes no cenário de 'Outros sujeitos, Outras pedagogias' de Miguel Arroyo (2014).

\section{O Reconhecimento das Experiências de Vida do Sujeito Discente}

Entender a dimensão de singularidade que perpassa a prática docente e a relação com a construção histórica da educação nos remete aos aspectos pedagógicos que sustentaram a tradicional engrenagem ensino-aprendizagem, fundamentada em teorias caracterizadas pela reprodução pragmática em que professor-ensina e aluno-aprende. Se contrapondo, ampliamos a reflexão para a pedagogia histórico-crítica, onde "educação é o ato de produzir, direta e intencionalmente, em cada indivíduo singular, a humanidade que é produzida histórica e coletivamente pelo conjunto dos homens" (SAVIANI, 2011. p. 2). 
A característica moderna da fluidez humana constitui-se aqui aspecto relevante para pensar em formas de orientação e condução das relações com as pessoas e com o mundo. Bauman (2001) na perspectiva líquida de abordar os processos de emancipação, individualidade, tempo e espaço, trabalho, comunidade, retrata mudanças da sociedade, que se reflete em um processo de transição de estados sólidos de se relacionar consigo e com o mundo, para uma visão de liquidez.

Essa liquidez traz a compreensão para mudanças de valores e novos modelos para a sociedade, a vida em sociedade encontra outras formas de fluir, e o seu nível de fluidez, portanto, vai determinar a inserção na sociedade, nos meios, nos grupos e tribos, sendo a característica maleável então, a ferramenta na conquista do espaço, da autonomia e do reconhecimento do processo de subjetivação humana.

Os termos continuamente utilizados são "indivíduo e individuação, que dizem respeito ao processo e compreensão da sociedade por parte do indivíduo e, a partir disso, e sua própria formação psíquica e social" (BAUMAN, 2001, p. 137). Subjetividade é um termo amplo para designar aquilo que identifica o sujeito em suas características internas e formas de expressão individualizada de como percebe o mundo, sente e o representa. Usado para identificar a condição intrínseca de ser humano (STELLA, 2007).

É esse indivíduo subjetivado que encontramos nos espaços de educação, que nos demandam processos de aprendizagem, um indivíduo em si potencialmente cognitivo, que sente, pensa, interpreta e agi constantemente em seu ambiente, na sociedade e se relaciona naturalmente com seu contexto, buscando atender as mais variadas demandas emergentes da vida cotidiana, transformando suas experiências em conhecimento e potencializando elementos intrapessoais para processos de aprendizagem nas relações entre o fazer humano e seu contexto social.

O que temos é reflexo de um processo de objetivação da realidade, que passou a mecanizar sujeitos, institucionalizando-os, fazendo com que os mesmos respondessem cada vez mais às necessidades econômicas contemporânea, não dando conta da realidade da vida cotidiana, repleta de processos de interiorização, onde cada sujeito constrói seu próprio conhecimento da realidade, a partir relações intersubjetivas que expressam as representações simbólicas das experiências entre os sujeitos, suas crenças, suas construções culturais, valores e significados da vida em sociedade (BERGER; LUCKMANN, 2012).

Nesse cenário se constitui o discente e a busca de compreender a dinâmica atual da realidade social que nos coloca diante do desafio de ampliar o olhar para a nova geração, afinada com os avanços tecnológicos, com a quantificação, com os resultados mensuráveis, sujeitos das 
objetivações da sociedade, que por vezes ignoram que coexistem realidades, cada sujeito com a sua, e a sociedade por sua vez, representa a construção subjetiva e objetiva da realidade de cada um de nós (BERGER; LUCKMANN, 2012; ARROYO, 2014).

Assim, nos reportamos Moran (2013) que amplia o olhar para a Educação Humanista, na busca de entender as emoções intricadas nos processos de aprendizagem e, a necessidade de significações naquilo que se aprende.

\begin{abstract}
A educação só faz sentido se se preocupa com as pessoas como um todo, com a sua inteligência, sensibilidade, emoção, atitudes e valores. A educação faz sentido se for integral, integrada, abrangente. A educação humanista é o processo de ajudar as pessoas a que aprendam a evoluir em todas as dimensões, e para que consigam fazer melhores escolhas em todos os campos (MORAN, 2013, p.4).
\end{abstract}

Então, para humanizarmos a educação é necessário compreender o contexto em que ocorrem as práticas de aprendizado e principalmente quem são os sujeitos envolvidos nesse processo, de onde vem, onde vivem, quais são suas experiências anteriores, suas habilidades, como suas emoções implicam em sua construção de conhecimento, considerando principalmente o discente como um ser existente em seu próprio desenvolvimento e diante de suas próprias escolhas.

Nesse sentido, o psicólogo norte-americano Ausubel na década de 60 buscou compreender processos de aprendizagem e os aspectos cognitivos que funcionam de modo a potencializar o aprender, sobretudo as experiências anteriores cognitivamente registradas, aprendidas. Passou então a levantar propostas psicoeducativas que caracterizou sua Teoria da Aprendizagem Significativa, oportunizando o sujeito atribuir sentido ao processo de aprendizagem, considerando impreterivelmente a disposição para aprender, com uma abertura de interesse sem pré julgamento e a necessidade de o conteúdo ser potencialmente significativo, permitindo o envolvimento da realidade com a aprendizagem (PELIZZARI et al., 2002).

Movimentos de (re)significação das teorias pedagógicas frente a cada sujeito toma força em direção aos processos de descolonização, liberdade, autonomia, emancipação. Luta incessante emergente nos anos 60 e 70, com maior expressão de resistência através dos movimentos sociais e de rebelião, sobretudo de jovens, que refletem o enfrentamento da subalternidade no mundo até os dias atuais, nos colocando diante de novos sujeitos sociais, com o desafio de implementar teorias e práticas educativas emancipatórias, onde o sujeito seja reconhecido diante de suas necessidades e singularidade, como centro propulsor de própria sua aprendizagem (FREIRE, 2007; ARROYO, 2014). 
O sujeito discente é então constituído de historicidade, de valores, representação e significados, alvo de demandas políticas e sociais emergentes no cenário atual, produto e produtor do sistema tecnologizado que busca atender aos anseios da economia, mecanizando as relações e suprimindo o potencial humano de manejo de suas próprias necessidades e conquistas, e por vezes, esse sujeito busca a lugar para liberdade e autenticidade no ensino superior, entendendo este como lugar de sujeitos predominantemente jovens e adultos que sinalizam resistência ao sistema vigente (PIMENTA, 2014; ARROYO, 2014).

\section{Contribuições da Andragogia para o Ensino Superior}

Os estudos sobre andragogia tem suas primeiras reflexões na década de 20 e de modo progressivo vem ocupando espaços de discussão e aplicação cada vez mais significativos. Hoje a educação de adultos tem ganhado notoriedade para a Organização das Nações Unidas para a Educação, a Ciência e a Cultura (UNESCO), ampliando as possibilidades políticas e científicas cada vez mais pautadas na realidade vivida pelos docentes e discentes no âmbito da educação de jovens e adultos e, de modo especial, no ensino superior (MENDES, 2014).

A andragogia é abordada como arte e ao mesmo tempo como ciência, com propósito de orientar adultos a aprender. Knowles (1995) acentuou os estudos e caracterizou andragogia pela necessidade de reconhecer as mudanças nos processos de aprendizagem em cada fase do desenvolvimento, entendendo que a criança aprende diferente do jovem e do adulto. $\mathrm{O}$ adulto dever ser o sujeito da centralidade no processo de aprendizagem e elemento produtor da mesma, o professor aqui atua como mediador, contribuindo com a reflexão e possibilidades autonomia discente (MENDES, 2014).

O cenário do ensino superior demanda então, contribuição para com a aprendizagem de adultos, onde o docente precisa manejar métodos que contemplem o conteúdo, o contexto, a aplicabilidade e principalmente as necessidades reais dos sujeitos aprendentes, elementos que estão para além daquilo que tradicionalmente as teorias pedagógicas nos oferecem. É necessário também motivar o discente, estimular sua prontidão para aprender, e então promover envolvimento e interesse consciente, atribuindo sentidos práticos junto ao sujeito auto direcionado com suas experiências e necessidade de conhecimento (CAVALCANTI, 2017).

A andragogia se apresenta aqui como ferramenta para potencializar as práxis no ensino superior, contribuindo para construção do conhecimento a partir dos pressupostos andragógicos de acordo com Rocha, pautados na autonomia, humildade, iniciativa, dúvida, mudança de rumo, 
contextos, experiência de vida, busca, objetividade e valor agregado, assim, "o adulto aprende mais e melhor quando percebe que lhe é dada a autonomia para o seu crescimento pessoal e profissional" (ROCHA, 2012, p.2).

As demandas discentes no ensino superior refletem processos de transformações, resistências e equilíbrio para com a realidade social, emancipação, profissionalização, ascensão, dentre ouras facetas típicas da vida adulta. A abordagem andragógica no ensino superior por sua vez, atende a essas necessidades em completude a pedagogia, entendendo a fase de transição da juventude à adultez e a atuação em um campo da aprendizagem de adultos em formação.

Nesse sentido, a andragogia se torna complementar a pedagogia, no entanto as questões necessárias se fazem em torno da formação docente, como se dar o processo de ensinagem, formas de abordar o processo de construção de conhecimento com visão ampliada sobre o sujeito discente e as demandas contemporâneas, não anulando os construtos até então, mas refletindo sobre as práticas, (re) avaliando e atribuindo novas ferramentas didáticas e metodológicas para atuação no ensino superior (MENDES et al., 2014).

\section{Considerações Finais}

A docência nos coloca diante de constantes e incessantes reflexões, sobre o saber, o poder e o fazer da prática docente, os manejos possíveis frente às demandas profissionais, institucionais e processos de construção do conhecimento no Ensino Superior. Diversas críticas se estabelecem diante das teorias liberais pela característica que enraíza a coletividade em uma perspectiva generalista, ao mesmo tempo igualitária e individualista, que objetiva o ser humano, suas relações e processos de aprendizagens.

É necessário entender a prática docente como uma ferramenta potencialmente de mediação, onde o sujeito discente deve ser envolvido, estimulado, motivado, incentivado a atribuir sentido àquilo que aprende $\mathrm{e}$, transformar a aprendizagem em conhecimento para si $\mathrm{e}$ para suas relações cotidianas, seja de trabalho, com a família ou com a sociedade em geral.

A educação demanda de uma releitura humanizada, que aborde os processos de ensino, aprendizagem e construção de conhecimento de modo que haja envolvimento significativo, relação harmônica do docente e do discente com o conteúdo, objetivos e interesses subjetivos e coletivos no ensino superior.

As práticas enraizadas no tradicionalismo da 'educação bancária' encontram forças contrárias em vários âmbitos e, muitos teóricos fazem de seus estudos, portas para repensarmos 
e reconstruirmos as práxis didáticas, com olhar multidimensional, compreendendo que atuar no ensino superior requer formação inicial e continuada orientada à docência, as práticas pedagógicas e andragógicas aplicadas à docência do ensino superior. Refletir é aqui condição sine qua non para uma práxis docente íntegra e propulsora.

Entende-se então, a necessidade de adotarmos uma perspectiva crítico reflexiva, pautada nas demandas emergentes e nas políticas vigentes, considerando a experiência de vida e a dimensão subjetiva na construção do conhecimento, ampliando o olhar ao subjetivo descolonizado, ativo em suas escolhas e co-responsável pelo seu espaço e seu fazer social. Desse modo, o uso de uma abordagem andragógica no ensino superior não sinaliza atendermos necessariamente aos adultos que temos, mas sim aos adultos que buscamos potencializar através do espaço acadêmico.

\section{Referências}

ARROYO, M.G. Outros sujeitos, outras pedagogias. 2 ed. Petrópolis, Rio de Janeiro. Vozes, 2014.

BERGER, P; LUCKMANN, T. A construção social da realidade. 34ª Ed. Petropolis: Vozes, 2012.

BRASIL, Ministério da Educação. Instituto Nacional de Estudos e Pesquisas Educacionais Anísio Teixeira - INEP. Censo 2015. Brasília, 2016. Disponível em: <http://portal.inep.gov .br/web/guest/educacao-superior-censo>. Acesso em 4 nov. 2017.

CAVALCANTI. R. A. Andragogia na educação universitária. Disponível em: <http://www.wr3ead.com.br/UNICEAD/andragogia_na_educacao_universitaria.pdf.>. Acesso em 25 fev. 2018

FREIRE, P. Educação e Mudança. 30ª Ed. Rio de Janeiro: Paz e Terra, 2007.

GOERGEN, P. Pós-modernidade, ética e educação. 2.ed. Campinas: Autores Associados, 2005.

LIBÂNEO, J. C. Reflexibilidade e formação de professores: outra oscilação do pensamento pedagógico brasileiro? in PIMENTA, S. G. P; GHEDIN, E; (Orgs.). Professor Reflexivo no Brasil. 4. ed. São Paulo: Cortez, p.53 - 80, 2006.

LOBO, M. B. M. Panorama da Evasão no Ensino Superior Brasileiro: Aspectos Gerais das Causas e Soluções. Instituto Lobo para Desenvolvimento da Educação, da Ciência e da Tecnologia. ABMES. Cadernos n 25. dez de 2012.

MENDES, M. 2014. Andragogia: um novo olhar sobre a formação docente. Rio de Janeiro-RJ. Abril - 2014. Disponível em: <http://www.abed.org.br/hotsite/20-ciaed/pt/anais/pdf/46.pdf>. Acesso em 10 mar. 2018. 
MENDES, M. C; LOPES, V.C; SOUZA, H.A; DELAINE, G.V; BUENO, S. V. Andragogia, métodos e didática do ensino superior: novo lidar com o aprendizado do adulto na ead. 2012. Disponível em: <http://www.abed.org.br/congresso2012/anais/218c.pdf>. Acesso em: 31 mar. 2018.

MORAN, J. M. Razão e emoção: componentes fundamentais do conhecimento. $5^{\circ}$ Simpósio Hipertextos e Tecnologias na Educação. $1^{\circ}$ Colóquio Internacional de Educação com Tecnologias. Recife: UFPE, 2013. Disponível em: <http://www.simposiohipertexto.com.br/2013/07/15/razao-eemocao-componentes-fundamentais-do-conhecimento/>. Acesso em: 25 fev. 2018.

PELIZZARI, A; KRIEGL, M. de L; BARON, M. P; FINCK, N. T. L; DOROCINSKI, S. I. Teoria da aprendizagem significativa segundo Ausubel. Rev. PEC, Curitiba, v.2. n.1. p.37-42. jul. 2001jul. 2002. Disponível em: <http://portaldoprofessor.mec.gov.br/storage/materiais /0000012381.pdf>. Acesso em: 19 abr. 2018.

PIMENTA, S. G. P. Formação de Professores - Saberes da Docência e Identidade do Professor. Nuances. Vol. III. Set. 1997.

PIMENTA, S. G. P; ANASTASIOU, L. das G. Docência no Ensino Superior. 5. ed. São Paulo: Cortez, 2014.

PIMENTA, S. G. P; GHEDIN, E; (Orgs.). Professor Reflexivo no Brasil. 4. ed. São Paulo: Cortez, 2006.

ROCHA, E. F. Os dez pressupostos andragógicos da aprendizagem do adulto: um olhar diferenciado na educação do adulto. Disponível em: <http://www.abed.org.br/ arquivos/os_10_pressupostos_andragogicos_enilton.pdf>. Acesso em: 05 de abr. 2018.

SAVIANI, D. Pedagogia histórico-crítica: primeiras aproximações. 11.ed.rev. Campinas - SP: Autores Associados, 2011.

ShIROMA, E. O; MORAES, M. C. M de; EVANGELISTA, O. Política Educacional. 4. ed. Rio de Janeiro: Lamparina, 2007.

STELLA, C. Subjetividade e Cutura: Perspectivas da Psicologia do Cotidiano In Nucleo de Estudos e Pesquisas Psicossociais do Cotidiano - NEPPC, Org. Introdução à Psicologia do Cotidiano. São Paulo: Expressão e Arte Editora, p 137 - 148, 2007.

Como citar este artigo (Formato ABNT):

TEIXEIRA, Alcylanna Nunes; GOMES FILHO, Antoniel dos Santos; BRITO, Tamyris Madeira de; QUEIROZ, Zuleide Fernandes de. Reflexões sobre as Práticas Docentes e o Sujeito Discente no Ensino Superior: Contribuições da Andragogia. Id on Line Rev.Mult. Psic., 2019, vol.13, n.43, p. 340-352. ISSN: 1981-1179.

Recebido: 29/11/2018;

Aceito: $30 / 11 / 2018$ 